\title{
FEM modeling of crack nucleation and crack propagation fretting fatigue maps: plasticity effect
}

\author{
C. Gandiolle ${ }^{1^{*}}$, S.Fouvry ${ }^{1}$
}

camille.gandiolle@ec-lyon.fr, siegfried.fouvry@ec-lyon.fr

${ }^{1}$ LTDS, Ecole centrale de Lyon, 36 avenue Guy de Collongue, 69134 Ecully Cedex, France

\section{Highlights}

- Experimental HCF Fretting Fatigue response under severe plastic loadings

- Better prediction of crack nucleation risk by modeling the contact plastic deformation

- Better prediction of crack arrest condition by modeling fretting induced residual stresses

- Fast method to establish infinite endurance Fretting Fatigue map

\begin{abstract}
Fretting fatigue life is a strategic issue for modern industries. Various strategies have been proposed to predict finite endurance fretting fatigue behavior. For long term assemblies, "infinite » endurance is preferred. This concept was rationalized using a so-called fretting-fatigue map which plots crack nucleation and crack arrest boundaries as functions of fatigue stress and fretting force. This mapping concept was established experimentally coupling plain fretting, fatigue and fretting fatigue experiments. It was also simulated using FEM elastic simulation. The correlation was good as long as elastic stress conditions were imposed. However, once significant plastic deformation was generated in the contact the elastic prediction induced a significant discrepancy. In the frame of this work we investigated how the integration of plasticity in the modeling strategy could improve respectively the crack nucleation and crack arrest boundaries predictions. The influence of plastic deformation on contact pressure profiles and the role of residual stresses were discussed.
\end{abstract}

Keywords: Fretting-fatigue; infinite endurance; FEM; plasticity; cracking 


\section{Nomenclature}

$\begin{array}{ll}b_{p} & \text { Maximum projected crack length } \\ d_{c} & \text { Crossland cracking risk } \\ E & \text { Young's modulus } \\ E_{\%} & \text { Relative prediction error } \\ \mathrm{K}_{1} & \text { Mode I stress intensity factor (SIF) } \\ \mathrm{K}_{\mathrm{PDT}} & \text { Slope of the normalized potential } \\ \mathrm{L} & \text { Length of cylinder pad } \\ \mathrm{P} & \text { Linear normal force } \\ \mathrm{p} & \text { Surface pressure } \\ \mathrm{p}_{0} & \text { Maximum surface pressure } \\ \mathrm{Q} & \text { Linear tangential fretting force } \\ \mathrm{q} & \text { Surface shear } \\ \mathrm{Q}^{*} & \text { Linear tangential fretting force amplitude } \\ \mathrm{q}_{\max } & \text { Maximum shear stress } \\ \mathrm{R} & \text { Radius of cylinder pad } \\ \mathrm{R}_{\mathrm{F}} & \text { Fatigue stress ratio } \\ \mathrm{R}_{\mathrm{K}} & \text { SIF stress ratio } \\ \mathrm{R}_{\mathrm{Q}^{*}} & \text { Fretting stress ratio }\left(\mathrm{Q}_{\min } / \mathrm{Q}_{\max }=\mathrm{Q}^{*}+/ \mathrm{Q}^{*}-\right) \\ \mathrm{S} & \text { Deviatoric part of } \Sigma\end{array}$

$\begin{array}{ll}\text { Subscripts } & \\ \text { CA } & \text { Crack arrest } \\ \text { CN } & \text { Crack nucleation } \\ \text { E } & \text { Elastic } \\ \text { EP } & \text { Elastic-plastic } \\ \text { FF } & \text { Fretting fatigue }\end{array}$

Greek letters

$\mathrm{J}_{2, \mathrm{a}}$

$\ell$

$\mu=\mu_{\mathrm{t}}$

$\Delta \mathrm{K}_{\text {eff }}$

$\Delta \mathrm{K}_{\mathrm{th}}=\Delta \mathrm{K}_{0}$

$\Sigma$

$\delta$

$v$

$\sigma_{\mathrm{C}}$

$\sigma_{\mathrm{d}}$

$\sigma_{\mathrm{H}, \max }$

$\sigma_{\max }=\sigma_{\mathrm{F}}$

бUTS

$\sigma_{\mathrm{y}, 0.2 \%}$

$\tau_{\mathrm{d}}$
Amplitude of the second invariant of the stress tensor deviator Critical distance

Coefficient of friction at the sliding transition

Effective SIF range

Crack arrest SIF threshold condition

Stress tensor

Fretting displacement

Poisson's coefficient

Equivalent stress of Crossland's criterion

traction-compression fatigue limit $\left(R_{F}=-1\right)$

Maximum value of the hydrostatic pressure

Maximum fatigue stress

Ultimate tensile strength of the plane material

Yield stress

Torsion fatigue limit $\left(R_{F}=-1\right)$ 


\section{Introduction}

Fretting is defined as a small oscillatory movement between two bodies in contact. Combined with cyclic bulk fatigue loading, so-called fretting-fatigue loading can induce catastrophic damage such as wear or cracking, which critically reduces the endurance of assemblies [1,2]. This study focused on infinite endurance response concerning cracking failure and was thus restricted to the partial slip domain. Below a certain fretting fatigue threshold, no crack is nucleated and the system runs under a safe crack nucleation condition. Above this threshold, a crack will nucleate but not necessarily propagate; higher stresses lead to crack propagation until failure (Fig. 1). The fretting fatigue endurance was extensively investigated in the past decades. Petiot et al. [3] and Szolwinski and al. [4] first applied multi-axial fatigue criterion to predict the crack nucleation risk. Predictions were improved by considering the severe stress gradients imposed by the contact loading, using non-local process volume stress averaging strategy [5] or equivalent critical distance [6]. The prediction of crack arrest was addressed by Araujo et al. [7] applying a short crack regime strategy. Combining both crack nucleation, short and long crack propagation rates, various numerical strategies were developed to predict the finite endurance fretting fatigue behavior [8-10].

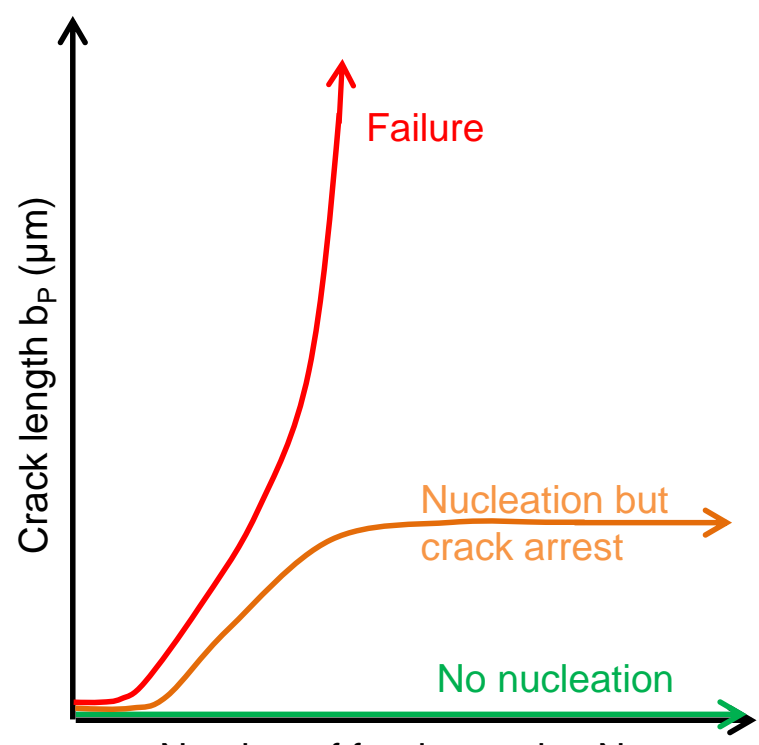

Number of fretting cycles $\mathrm{N}$

Fig. 1. Crack nucleation and propagation in fretting-fatigue. 
Prediction of the infinite endurance response was rationalized using a fretting-fatigue map concept introduced in [11]. This fretting fatigue map approach plots both crack nucleation and crack arrest boundaries as functions of fatigue loading defined by the maximum fatigue stress ( $x$-axis) and fretting loading defined by the fretting tangential force (y-axis) (Fig. 2). As in any fatigue problem, the mean stress plays a critical role in damage evolution. The mapping description is thus relevant for given fatigue $R_{F}$ and fretting $R_{Q^{*}}$ stress ratios, and a given contact configuration. This mapping concept was established experimentally coupling plain fretting, fatigue and fretting fatigue experiments. It was also simulated using FEM elastic simulation. The correlation was good as long as elastic stress conditions were imposed. However, once significant plastic deformation was generated in the contact the elastic prediction showed significant discrepancies.

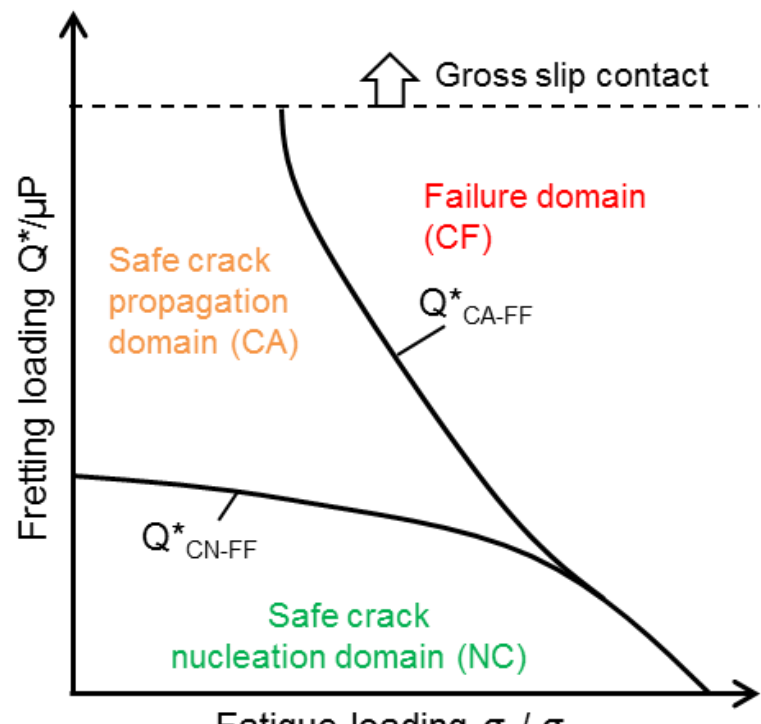

Fatigue loading $\sigma_{\mathrm{F}} / \sigma_{\mathrm{y}, 0.2 \%}$

Fig. 2. Fretting fatigue map: $Q^{*}{ }_{C N-F F}$ crack nucleation boundary, $Q^{*} C A-F F$ crack arrest boundary. NC: no crack nucleation, CA: crack arrest domain, CF: crack failure domain.

In the frame of this research work we investigated in how far the integration of plasticity in the modeling strategy could improve the prediction of crack nucleation and crack arrest boundaries. The result was then discussed regarding computational costs. These considerations are crucial aspects for fretting fatigue design industry. 


\section{Experiments}

\subsection{Material}

In this study, a $32 \mathrm{Cr} 1$ steel, characterized by an isotropic hardening, was subjected to fretting fatigue $(E=200 \mathrm{GPa}$ and Poisson's ratio $v=0.3)$. Its atomic composition is: $0.32 \% \mathrm{C}, \quad 0.347 \% \mathrm{Cr}, \quad 0.743 \% \mathrm{Mn}, \quad 0.201 \% \mathrm{Si}, \quad 0.046 \% \mathrm{Cu}, \quad 0.016 \% \mathrm{Mo}, \quad 0.047 \% \mathrm{Ni}$, $0.013 \% \mathrm{Al}, 0.007 \% \mathrm{P}, 0.002 \% \mathrm{~S}$ [12]. Fig. 3 plots the monotonic hardening of the studied steel which was obtained from a simple tensile test and normalized by the yield strength.

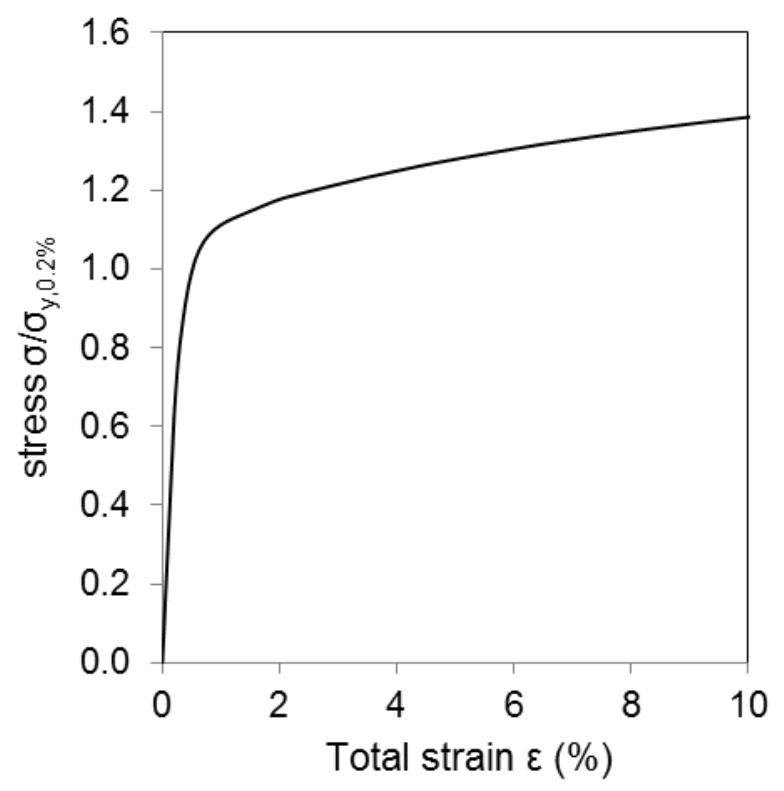

Fig. 3. Elastic plastic law of the studied material.

\subsection{Contact}

The fretting-fatigue response of the steel was investigated using a cylinder/plane configuration. The cylinder pad consisted of tempered 35NCD16 steel with a cylinder radius of $R=19 \mathrm{~mm}$ and a lateral width of $L=10 \mathrm{~mm}$ ( $E=200 \mathrm{GPa}, v=0.3$ ). It is applied on the plane with a high static normal force $P$. The contact was tested in plain fretting, plain fatigue and fretting-fatigue $[13,14]$. Scheme and photos of the fretting tests are illustrated in Fig. 4. The normal force $P$ was applied to the contact using a mechanical spring system for plain fretting tests and a hydraulic actuator for fretting fatigue tests. A hydraulic actuator was used to impose a purely alternating sinusoidal cyclic 
displacement $\delta(t)$ on the plane, generating an alternating cyclic tangential load $Q(t)$ on the contact surface. For fretting fatigue, a third actuator allowed separate application of the fatigue force on the flat sample (Fig. 4). A sinusoidal cyclic tangential force was applied in phase with the fatigue loading such that the maximum fretting load $\mathrm{Q}^{*}{ }_{\max }$ occurred at the same time as the maximum fatigue stress $\sigma_{\max }$. The imposed displacement was chosen small enough to be in partial slip so as to avoid gross slip conditions.

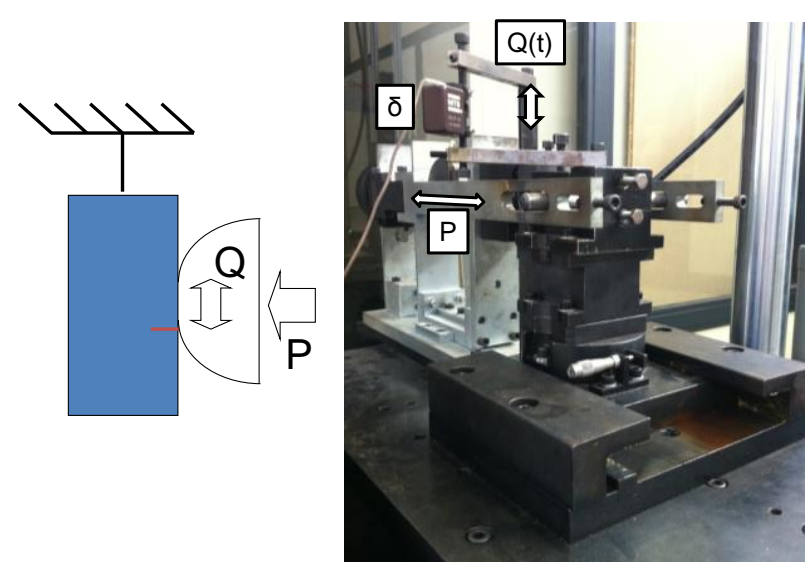

a-

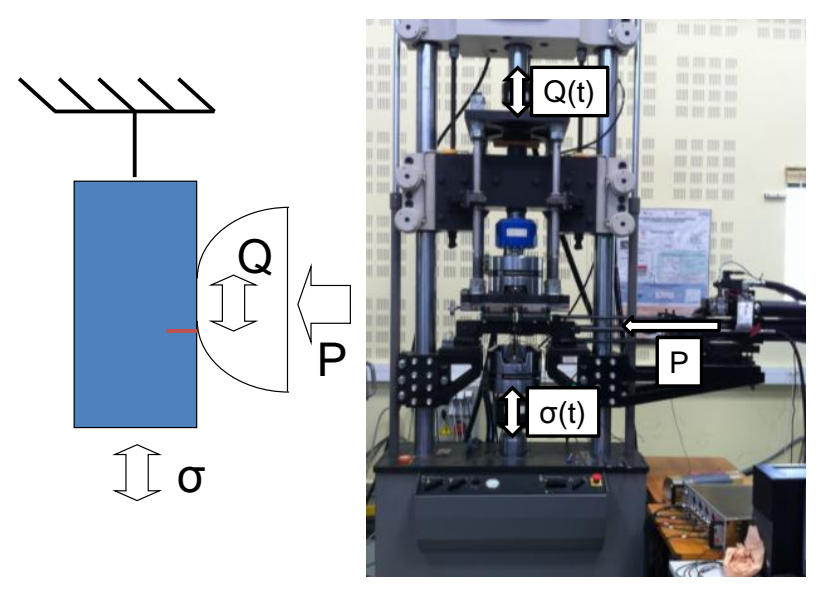

b-

Fig. 4. a- Scheme and photo of plain fretting test, b- scheme and photo of fretting fatigue test.

During the test, the displacement $\delta$, normal force $P$ and tangential force $Q$ were recorded, enabling the $Q-\delta$ fretting loop to be plotted and thus the fretting regime to be 
identified. Fig. 5 plots an example of a fretting loop. Its closed shape confirms the partial slip regime. Tests were performed at a frequency of 12 Hertz, high enough to investigate long test conditions and low enough to guarantee test control stability. The fatigue and fretting stress ratios were kept constant at $R_{F}=\sigma_{F, \min } / \sigma_{F, \max }=0.94$ and $R_{Q}=Q_{\min } / Q_{\max }=-$ $Q^{*} /+Q^{*}=-1$ respectively.

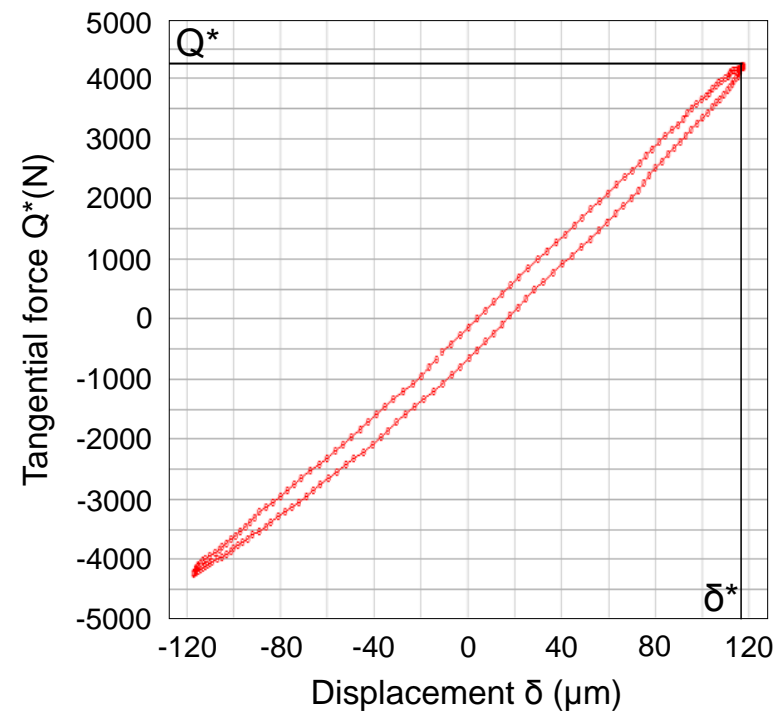

Fig. 5. Q- $\delta$ fretting loop

\subsection{Results}

\subsubsection{Expertise of crack nucleation}

Crack nucleation was studied at $10^{6}$ cycles. Crack analysis was restricted to the flat specimens. The chosen specimen dimensions provided plane strain conditions along the central axis of the fretting scar. All fretting scars were analyzed following a method developed by Proudhon et al. [15]. First, the sample is cut in the middle, and then imbedded in epoxy to be polished to a mirror-like surface state. Next, cracks are observed with an optical microscope. For each experiment, the maximum projected crack length $b_{p}$ was considered (Fig. 6), then plotted as a function of the tangential force amplitude $Q^{*}$. The crack nucleation condition $Q^{*}{ }^{*}$ was defined for the tangential load at which no crack can be observed (i.e. $b_{p}=0 \mu \mathrm{m}$ ). To determine this value, the evolution of crack length with tangential load was assumed to be linear, as plotted in Fig. 7. This strategy, usually applied for plain fretting condition, was applied for different fretting 
fatigue condition to establish the evolution of $Q^{*}{ }_{C N-F F}$ versus the fatigue stress thus to establish an experimental estimation of the fretting fatigue crack nucleation boundary.

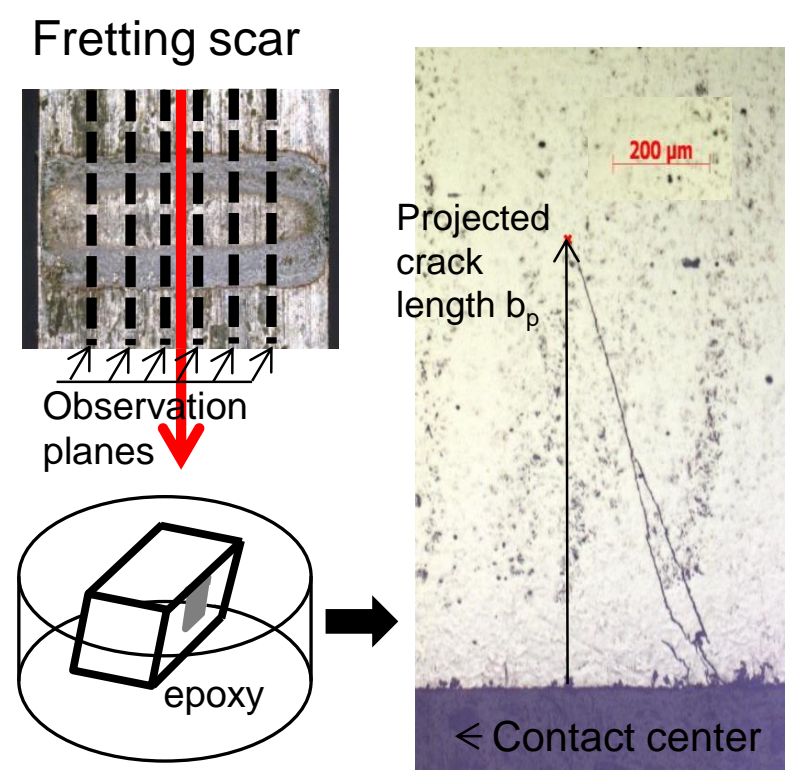

Fig. 6. Expertise method of crack length

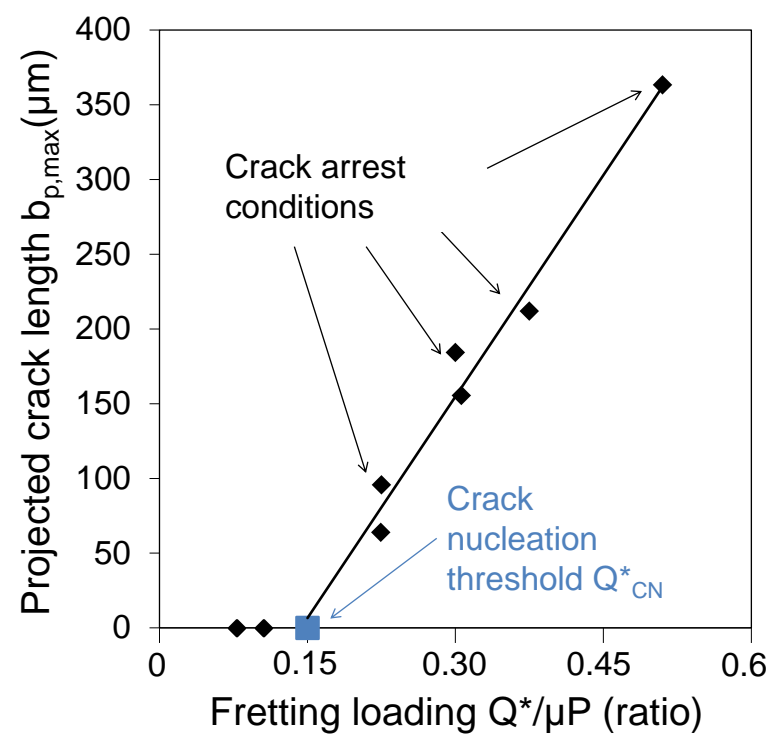

Fig. 7. Crack nucleation threshold $Q^{*}{ }^{*}$ determination obtained under plain fretting condition $Q^{*}{ }_{C N-F F}\left(\sigma_{F F}=0\right)=Q^{*}{ }_{C N}$ 


\subsubsection{Expertise of crack arrest}

The crack arrest condition was related to a crack propagation rate converging to zero. To observe crack propagation rate during the test, the potential drop technique (PDT) was implemented on the test sample (Fig. 8). The PDT is a well-known technique for observing crack propagation in fatigue tests. It has been widely used and the calibration procedure is well known. The idea of applying the PDT to a fretting fatigue device was first introduced by Kondo et al. [16] and transposed by Mériaux and al. [13] for double actuator fretting fatigue experiments. The technique relies on the fact that, for a given DC current, the distribution of the electrical potential in the vicinity of a crack changes with crack growth.

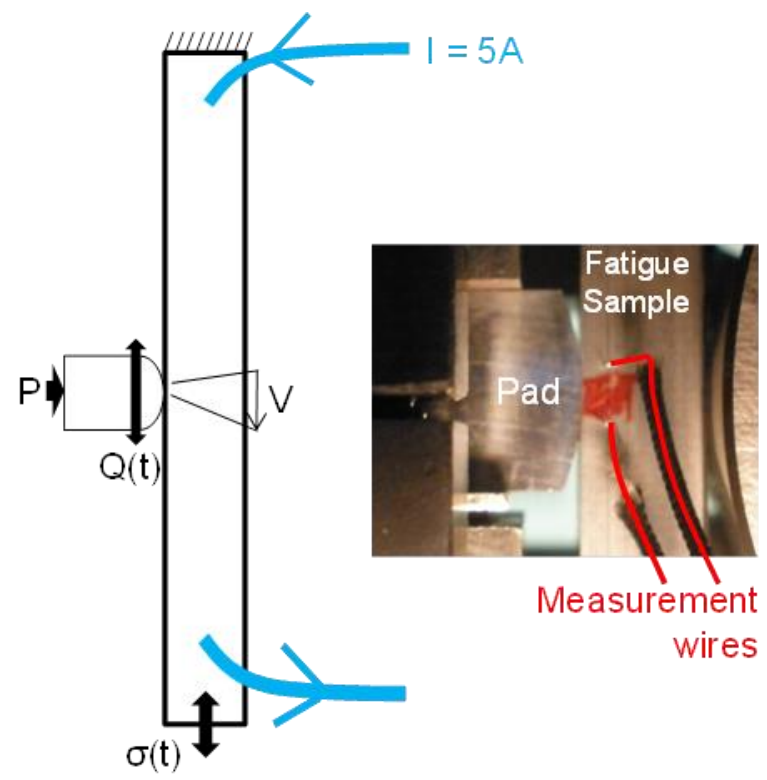

Fig. 8. Scheme of the implementation of the potential drop technique on fretting fatigue test

A 5A DC current was applied through the fatigue test sample. When a crack propagates, the distance of DC current is longer and electrical resistance increases. A variation in electrical potential is thus observed by the acquisition system. Taking the mean value of the potential measured on each side of the sample, possible non-homogeneity of crack propagation in the sample was taken into account. This method provides direct information on crack propagation, so only one non-destructive test was necessary to 
know whether a loading condition induced crack arrest or not. A criterion was established (Fig. 9) as follows:

- If the normalized potential slope as a function of the number of cycles remains smaller than $10^{-9}$, we assume a crack arrest condition (i.e. $\mathrm{K}_{\mathrm{PDT}<}<10^{-9} \rightarrow$ crack arrest)

- If $\mathrm{K}_{\mathrm{PDT}}>10^{-9}$ there is no crack arrest.

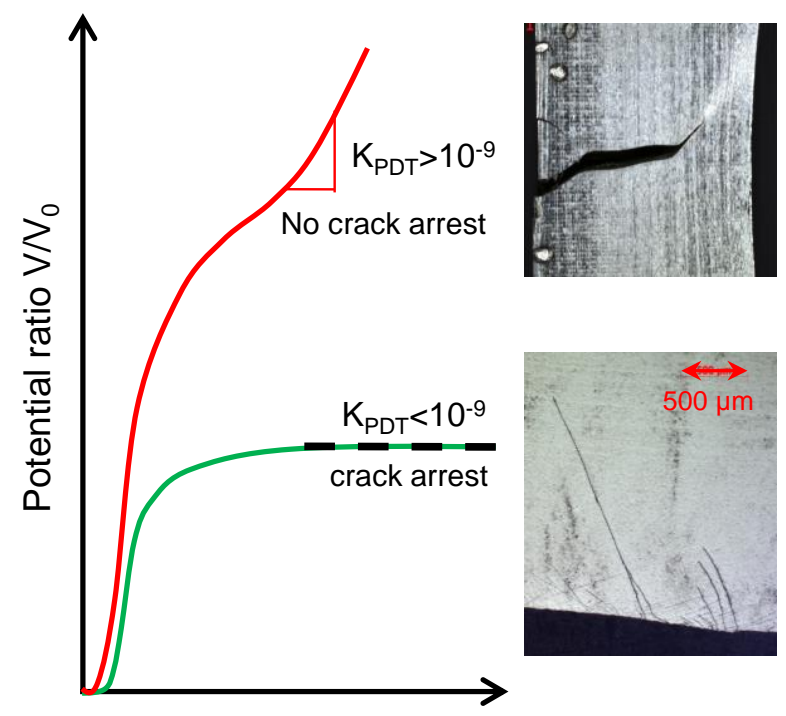

Fretting cycles $\mathrm{N}$

Fig. 9. Crack arrest criterion as a function of the potential slop

\subsubsection{Experimental results}

Fig. 10 plots the experimental fretting fatigue map obtained. Examining the crack nucleation boundary (i.e. $Q^{*}{ }^{*}$ N-FF) defined using the methodology developed in Fig. 7 $\left(Q^{*} \mathrm{CN}-\mathrm{FF} \rightarrow \mathrm{b}_{\mathrm{p}}=0 \mu \mathrm{m}\right)$, we observed that an increase of the fatigue stress did not induce an instantaneous decrease of the threshold fretting stress. A plateau evolution equivalent to plain fretting crack nucleation $Q^{*}{ }^{*}$ was observed. For technical aspects it was not possible to investigate the crack nucleation above $\sigma_{F} / \sigma_{y, 0.2 \%}=0.84$. However we guess a sharp decrease down to the fatigue limit $\sigma_{\mathrm{d} 0.94}$. As the studied stress ratio is close to 1 $\left(R_{\mathrm{F}}=0.94\right)$, we consider that $\sigma_{\mathrm{d} 0.94}=\sigma_{U T S}$. Regarding the crack arrest boundary, a continuous decrease of $Q^{*}$ CA-FF was observed until merging with the crack nucleation boundary when $\sigma_{F} / \sigma_{y, 0.2 \%}=1.05$. As expected crack arrest boundary never reached the 
$\sigma_{F}=0$ plain fretting condition. Plain fretting systematically induces a situation of crack arrest since the crack nucleated by contact loading cannot propagate if no bulk stresses are imposed.

Crack arrest process showed some scattering for high fretting ratios. A compromise was made to establish the experimental crack arrest boundary. It consisted in defining the intermediate fatigue stress marking the transition between crack arrest and non-crack arrest studied condition for each fretting $Q^{*} / \mu P$ level. Applying this simple experimental method both $Q^{*}{ }^{*}$-FF and $Q^{*}{ }^{*}$ A-FF versus the fatigue stress were established using a limited number of fretting fatigue tests. The boundary was then extrapolated to the plain fatigue limit to define the crack arrest domain.

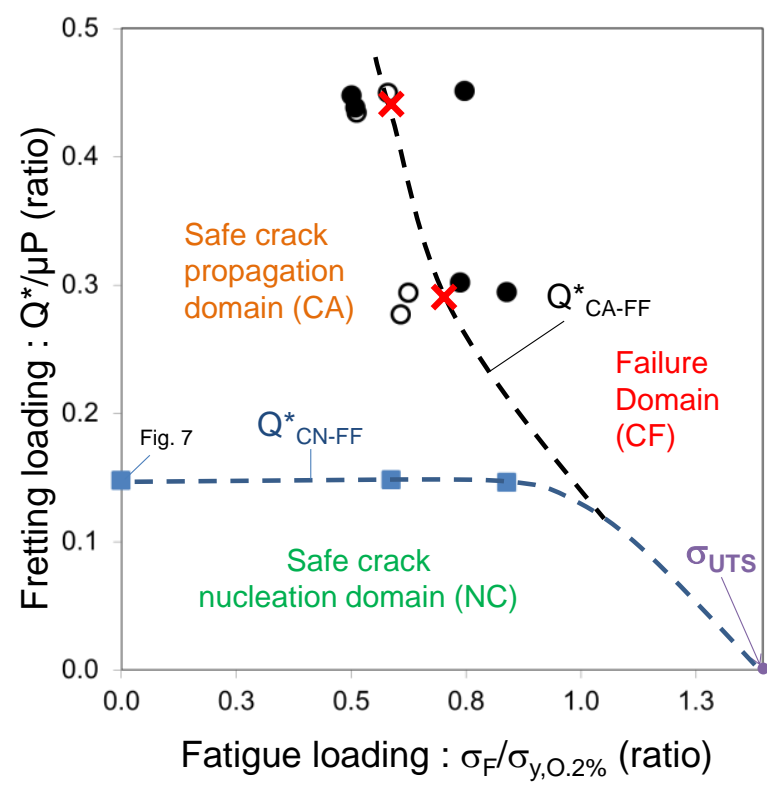

$\mathrm{O}: \mathrm{K}_{\mathrm{e}}<10^{-9}$, crack arrest after $10^{7}$ cycles

-: $K_{e}>10^{-9}$, failure or crack propagation after $10^{7}$ cycles

च: Crack nucleation limit involving at least 8 tests at $10^{6}$ cycles following the procedure developed in Fig. 7.

Fig. 10. Experimental crack nucleation (_-_, $\left.Q^{*}{ }_{C N-F F}\right)$ and crack arrest (_-_, $\left.Q^{*}{ }_{C A-F F}\right)$ boundaries in the fretting fatigue map. $\mathbf{X}$ : Experimental crack arrest conditions.

$$
\left(\mathrm{R}=19 \mathrm{~mm}, 12 \mathrm{~Hz}, \mathrm{P}, \mathrm{R}_{\mathrm{F}}=0.94, \mathrm{R}_{\mathrm{Q}^{\star}}=-1\right) .
$$




\section{Modeling strategy}

\subsection{Finite element model}

Finite element (FE) analysis was carried out using Abaqus 6.10 software. A 2D model of the fretting fatigue test was generated as shown in Fig. 11. The dimensions were conformed to the test considering plain strain conditions. The ball-bearing was shown to have no impact on the sample stress field; therefore, a symmetric condition was used with a significant width. The model was meshed with linear triangular elements type CPE3, except in the contact zone where linear quadrilateral elements type CPE4R were used. In addition, this zone was meshed more densely than the other regions $(5 \mu \mathrm{m}$ long squares). To simulate a plain fretting test, the plane part of the model was also restricted on left side and underneath.

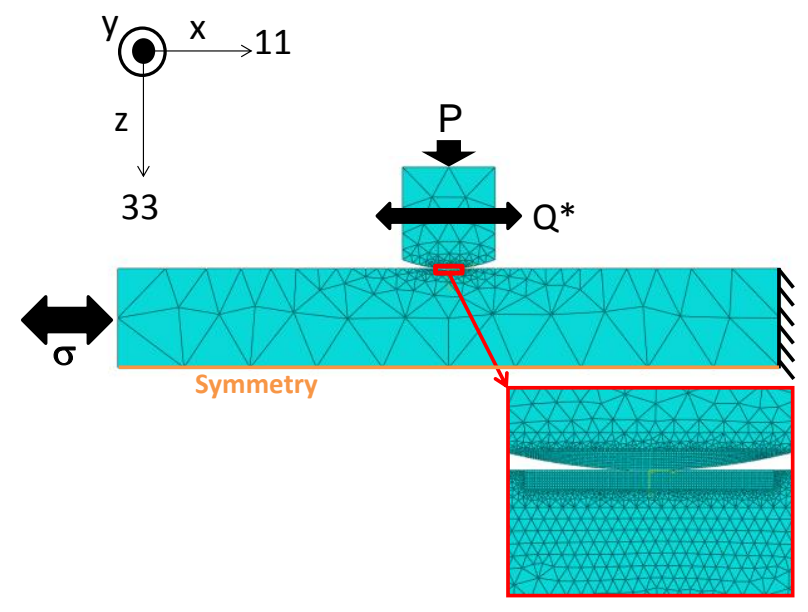

Fig. 11. Abaqus model of the test

Surface-to-surface discretization with small sliding was adopted for contact accommodation. The Lagrange multiplier was selected as the contact algorithm. Previous studies have shown that the friction coefficient at the sliding transition is also representative of the coefficient of friction in the sliding domains of the partial slip contact [17]. Friction coefficient at the sliding transition was determined experimentally with a variable displacement method [18]: $\mu_{\mathrm{t}}=\mu=0.8$ and was implemented as the friction coefficient of the Lagrange formulation in the FE model. The constraints, displacements and loads precisely represented the test conditions. 


\subsection{Crack nucleation criterion}

The Crossland criterion was used to identify a crack nucleation condition. Crossland's multiaxial fatigue criterion expresses crack risk as a linear combination of the maximum amplitude of the second invariant of the stress deviator defined by $\sqrt{J_{2, a}}$, and the maximum value of the hydrostatic pressure $\sigma_{H, \max }[19]$.

The non-cracking condition is expressed by:

$\sqrt{\mathrm{J}_{2, \mathrm{a}}}+\alpha \cdot \sigma_{\mathrm{h} \max }<\tau_{\mathrm{d}}$

where

$\sigma_{\mathrm{h} \max }=\max _{\mathrm{t} \in \mathrm{T}}\left(\frac{1}{3} \operatorname{trace}(\underline{\underline{\Sigma}}(\mathrm{t}))\right)$

$\sqrt{\mathrm{J}_{2, \mathrm{a}}}=\frac{1}{2} \max _{\mathrm{t}_{0} \in \mathrm{T}}\left\{\max _{\mathrm{t} \in \mathrm{T}}\left[\frac{1}{2}\left(\underline{\underline{S}}(\mathrm{t})-\underline{\underline{S}}\left(\mathrm{t}_{0}\right)\right):\left(\underline{\underline{S}}(\mathrm{t})-\underline{\underline{S}}\left(\mathrm{t}_{0}\right)\right)\right]^{1 / 2}\right\}$

$\alpha=\frac{\tau_{d}-\frac{\sigma_{d}}{\sqrt{3}}}{\frac{\sigma_{d}}{3}}$

The traction-compression and torsional fatigue limit values, $\sigma_{d}$ and $\tau_{d}$, were determined experimentally applying a staircase method by respectively tensile-compressive and alternating torsional tests. Cracking risk can then be estimated by comparing the equivalent Crossland stress

$\sigma_{C}=\sqrt{J_{2, a}}+\alpha \cdot \sigma_{h \max }$

with the torsion fatigue limit: for $\sigma_{C} \geq \tau_{d}$ there is a cracking risk. The cracking risk can also be formalized using a scalar variable: 
$d_{C}=\frac{\sigma_{C}}{\tau_{d}}$

The non-cracking condition is then expressed by $d_{c}<1$. If $d_{c}$ is greater than or equal to 1 , there is a cracking risk. The present study used this scalar variable to quantify cracking risk.

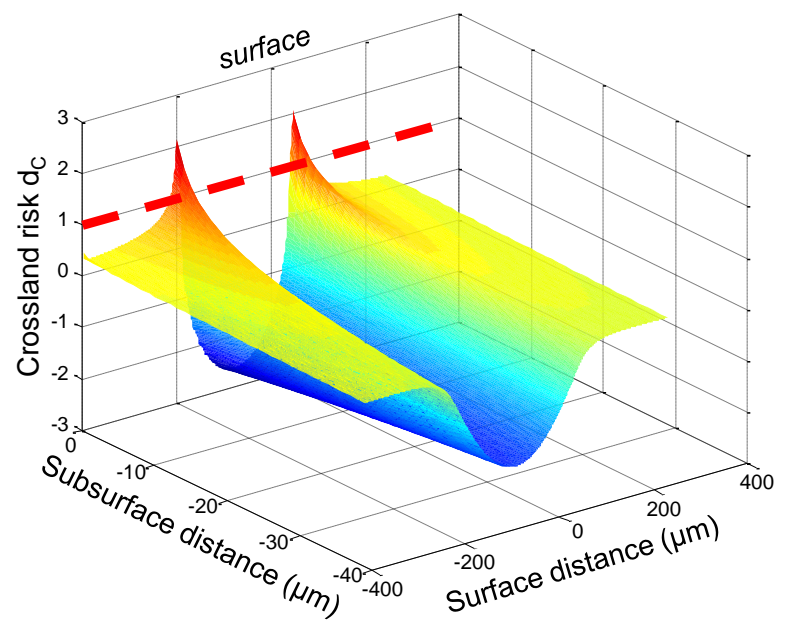

Fig. 12. Crossland cracking risk of plain fretting crack nucleation condition considering elastic conditions $\left(\mathrm{R}=19 \mathrm{~mm}, 12 \mathrm{~Hz}, \mathrm{Q}^{*} / \mu \mathrm{P}=0.15\right)$

Fig. 12 plots the subsurface distribution of the Crossland cracking risk related to the plain fretting crack nucleation condition. As previously underlined, the maximum cracking risk (i.e. hot spot stress) was located on the surface at the contact borders [20]. The computed value was significantly larger than the expected $d_{c}=1$ crack nucleation value and the distribution was characterized by very severe stress gradients.

\subsection{Crack arrest criterion}

A decoupled approach was used to predict the crack arrest boundary: the contact stress state was obtained by FEM (Fig. 13), then the mode I stress intensity factor (SIF) was calculated using a weight function approach [21]:

$\mathrm{K}_{\mathrm{I}}=\sqrt{\frac{2}{\pi}} \int_{0}^{\mathrm{h}} \mathrm{M}(\mathrm{t}) \cdot \sigma_{11}(\mathrm{t}) \mathrm{dt}$ 
With $M(t)=t^{-1 / 2} \cdot\left[1+m_{1} \cdot \frac{t}{h}+m_{2} \cdot\left(\frac{t}{h}\right)^{2}\right]$

And $m_{i}=A_{i}+B_{i} r^{2}+C_{i} r^{6}$

With $A_{1}=0.6147, B_{1}=17.1844, C_{1}=8.7822, A_{2}=0.2502, B_{2}=3.2889$ and $C_{2}=70.0444$.

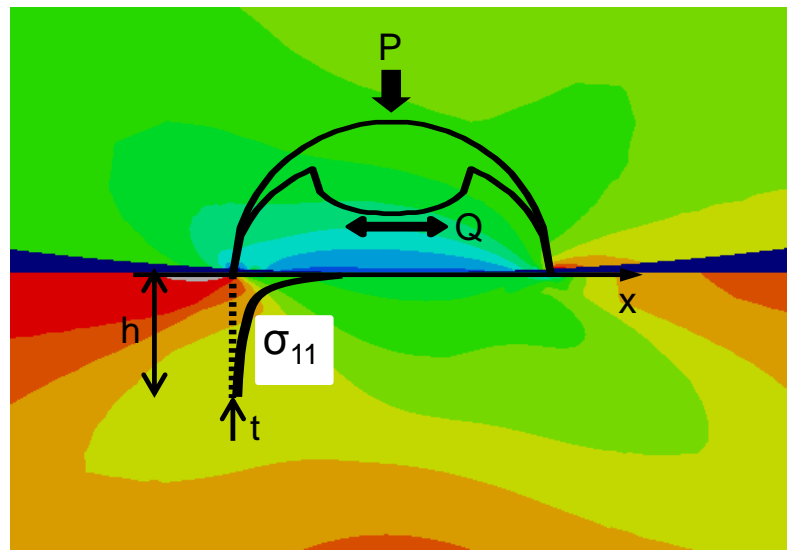

Fig. 13. Extraction of stress on the contact modeling

Finally the Elber approximation was used to obtain the effective stress intensity range along the crack [19]. The Elber approximation allows accounting for the crack closure effect induced by compressive conditions, defined by the $R_{K}=K_{\operatorname{Imin}} / K_{\operatorname{Imax}}$ ratio:

for $\mathrm{R}_{\mathrm{K}}>0, \Delta \mathrm{K}_{\mathrm{eff}}=\mathrm{K}_{\mathrm{lmax}}-4$

for $-1<R_{K}<0, \Delta K_{\text {eff }}=K_{\text {Imax }}-\left(4 . R_{K}+4\right)$

and for $\mathrm{R}_{K}<-1, \Delta \mathrm{K}_{\text {eff }}=\mathrm{K}_{\mathrm{Imax}}$

The contribution of mode II was neglected [5]. The crack arrest was reached when the effective SIF along the expected crack path crossed the material crack arrest threshold $\Delta K_{\text {th }}$ (Fig. 14). Note that in the present investigation the crack length transition from short to long crack regime was very small, about $b_{0}=50 \mu \mathrm{m}$, so that only a constant long crack hypothesis was assumed: $\Delta \mathrm{K}_{\mathrm{th}}=\Delta \mathrm{K}_{0}$. When the SIF did not cross the crack arrest condition, crack propagated until failure. Crack arrest was reached when the effective SIF tangentially reached the crack arrest limit. Some discontinuity in the evolution of $\Delta K_{\text {eff }}$ was due to the evolution of stress ratio $R_{K}$ below the interface where the $R_{K}$ ratio can be greater than -1 , leading to different Elber approximation of $\Delta \mathrm{K}_{\text {eff. }}$ 


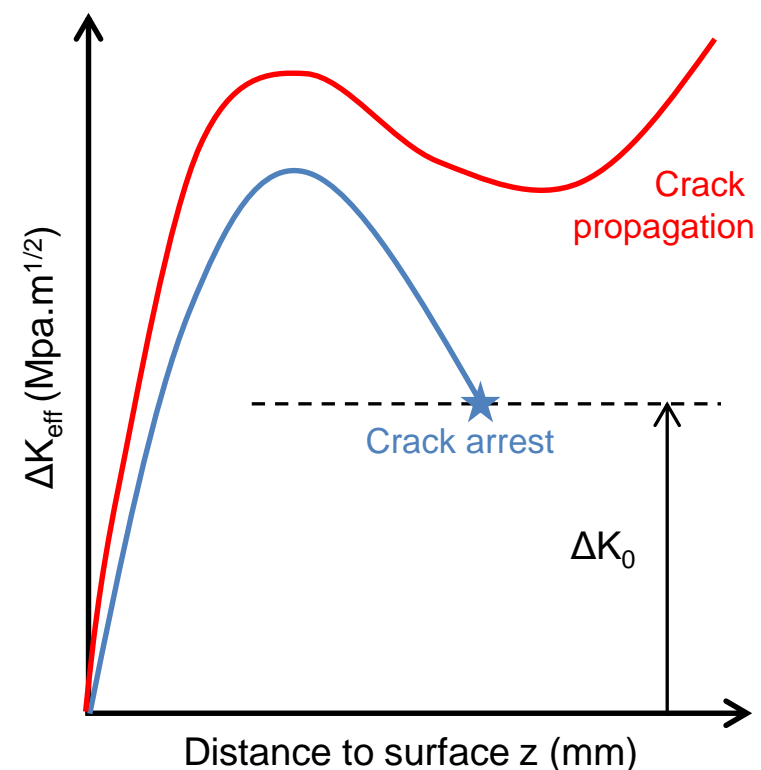

Fig. 14. Crack arrest condition

\section{Elastic prediction of the fretting fatigue map}

A strategy equivalent to the one developed in [11] is now applied for our studied interface assuming a fully elastic response.

\subsection{Crack nucleation boundary}

In Fig. 12 we observed that the local stress analysis at the hot spot greatly overestimates the fretting cracking. This is induced by a well-known stress gradient effect introduced by the fretting contact configuration.

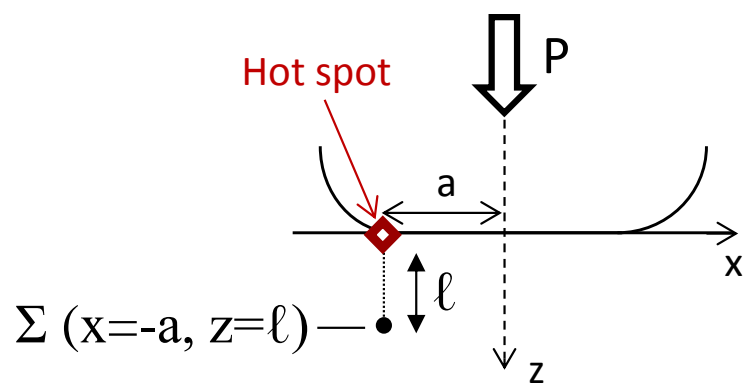

Fig. 15. Critical distance method with $\ell$ : critical length 
To palliate such misestimating of crack nucleation risk, a non-local fatigue stress analysis was applied [11]. The critical distance approach was considered. It is equivalent to point stress analysis but, instead of considering the surface hot-spot stress at the surface trailing contact border, fatigue analysis was performed at a critical distance below the surface ( $x=-a, z=\ell$, Fig. 15). This critical distance could be estimated with Taylor theory [22] but such estimation was shown to be not pertinent for very severe stress gradients like those induced by fretting stressing [20]. Alternatively the critical distance $\ell$ was calibrated by inverse identification on the experimental plain fretting crack nucleation condition $Q^{*}{ }^{*} / \mu P=0.15$ (Fig. 7). This condition was simulated considering a full elastic response of the plane. It showed that $\sigma_{C}=\tau_{d}$ if $\ell_{E}=20 \mu m$ (Fig. 16).

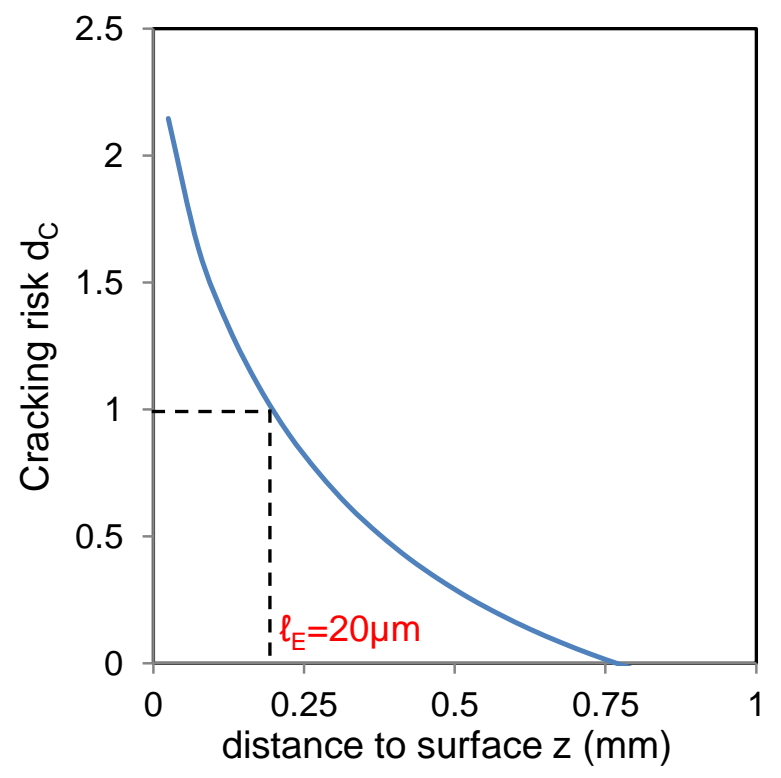

Fig. 16. Crossland cracking risk at contact border for plain fretting crack nucleation condition $Q^{*}{ }^{*}$ considering elastic conditions $\left(R=19 \mathrm{~mm}, 12 \mathrm{~Hz}, Q^{*} / \mu P=0.15\right)$

To establish the stability of this approach, the $Q^{*}$ CN-FF condition were computed for different fatigue stress conditions thus establishing an elastic estimation of the crack nucleation boundary of the fretting fatigue map (Fig. 17). The dotted line is an extrapolation until the plain fatigue limit. The computed boundary was really conservative compared to experimental results. As expected from an elastic stress description the $Q^{*}{ }_{C N-F F(E)}\left(\ell_{E}\right)$ crack nucleation boundary decreased linearly with the 
applied fatigue stress and was not able to describe the plateau evolution given by the experimental investigation.

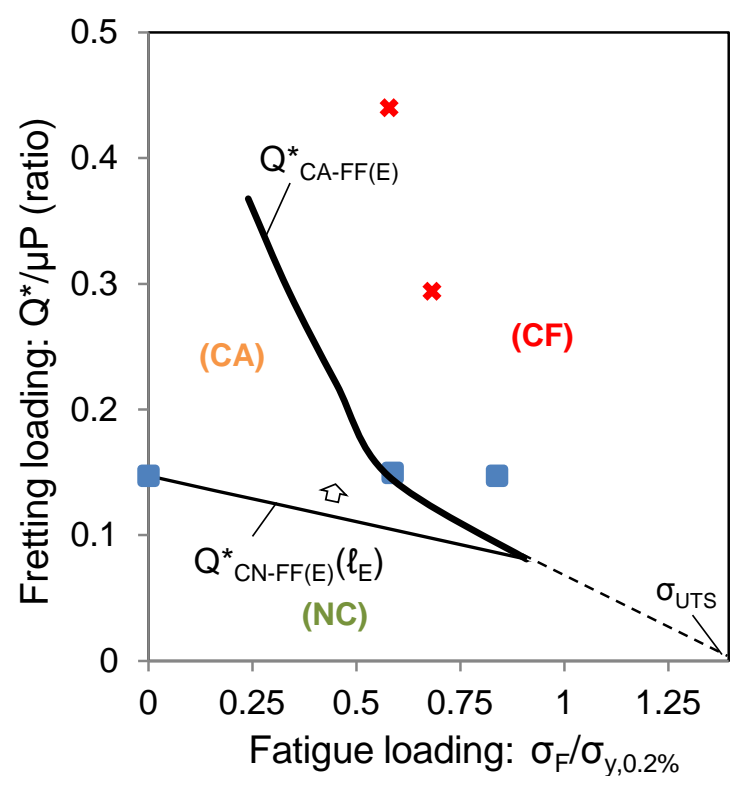

Fig. 17. Computed elastic crack nucleation $\left(-, Q^{*}{ }_{C N-F F(E)}\left(l_{E}\right)\right)$ and crack arrest $\left(-, Q^{*} C A-\right.$ $\mathrm{FF}(\mathrm{E}))$ boundaries in the fretting fatigue map. $\mathrm{X}$ : Experimental crack arrest conditions. $\mathrm{E}$ :

Experimental crack nucleation conditions. $\left(R=19 \mathrm{~mm}, 12 \mathrm{~Hz}, \mathrm{P}, \mathrm{R}_{\mathrm{F}}=0.94, \mathrm{R}_{\mathrm{Q}^{*}=-1}\right.$, $\left.\ell_{E}=20 \mu \mathrm{m}\right)$. (NC: no crack nucleation, $C A$ : crack arrest domain, $C F$ : crack failure).

\subsection{Crack arrest boundary}

As developed in section 3.3 a key factor controlling crack arrest condition is $\Delta \mathrm{K}_{0}$. Unfortunately this value was not known for the studied steel. To determine $\Delta \mathrm{K}_{0}$ crack arrest threshold required by the FF modeling, an inverse analysis [23] of crack arrest results achieved under plain fretting conditions was applied. Because no external fatigue stress was imposed, the plain fretting stress systematically leads to a crack arrest condition.

By computing the $\Delta \mathrm{K}_{\text {eff }}$ value related to each plain fretting crack lengths longer than $50 \mu \mathrm{m}$, an estimation of $\Delta \mathrm{K}_{0}$ could be achieved. This strategy was hence applied assuming an elastic response for computation (Fig. 18). A constant evolution was observed which allowed an extrapolation of long crack threshold value $\Delta \mathrm{K}_{0-\mathrm{E}}=2 \mathrm{MPa} \cdot \mathrm{m}^{1 / 2}$. 
This value is relatively low especially for a steel alloy. Using this value, crack arrest boundary estimation comparing the evolution of $\Delta \mathrm{K}_{\text {th }}$ for different fretting fatigue stress condition (Fig. 17) was applied. Like for the crack nucleation analysis, this elastic description of the crack arrest boundary was very conservative. The tendency was well described displaying a continuous decrease of the crack arrest boundary with the applied fatigue stress, but the computed $Q^{*}{ }^{*} A-F F(E)$ transition was shifted to smaller fatigue stresses compared to experimental results.

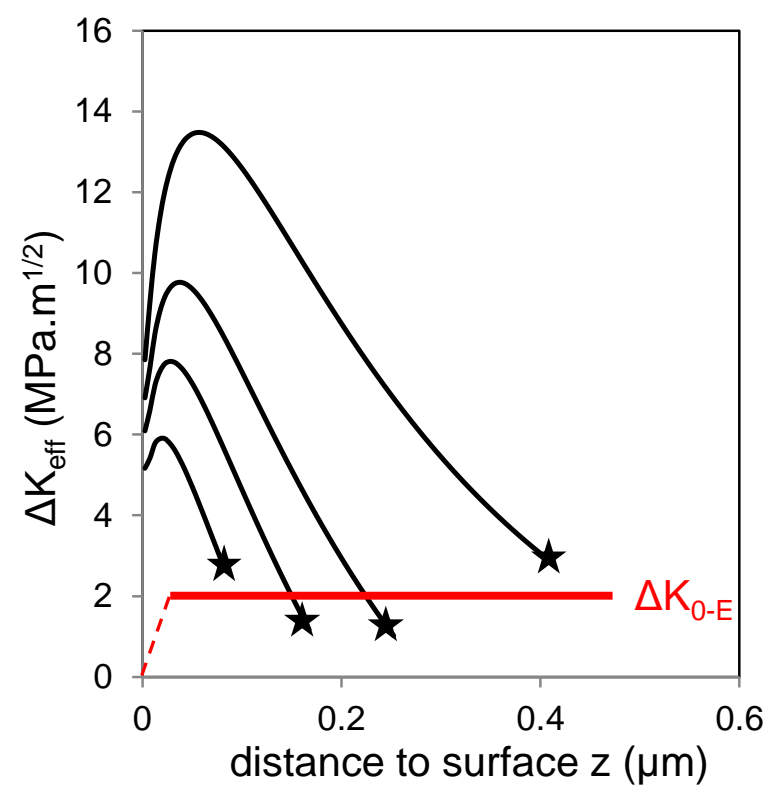

Fig. 18. Identification of the crack arrest condition under plain fretting $\left(10^{6}\right.$ cycles, $\left.12 \mathrm{~Hz}\right)$

\subsection{Synthesis}

Although the proposed methodology was calibrated using plain fretting crack experiments ( $\ell_{E}$ and $\Delta \mathrm{K}_{0-\mathrm{E}}$ ), we showed that elastic simulation of elastic-plastic fretting fatigue experiments leads to very conservative prediction of both crack nucleation $\left(Q^{*} \mathrm{CN}\right.$ $\left.{ }_{F F}\right)$ and crack arrest fretting fatigue boundaries ( $\left.Q^{*}{ }_{C A-F F}\right)$. 


\section{Monotonic elastic-plastic modeling of fretting fatigue map}

The monotonic plastic law was now considered and implanted (Fig. 3). When using this law to simulate the plane behavior in a fretting fatigue test modeling, the amount of activated plasticity decreased after each cycle, due partly to material hardening but mostly to plastic accommodation of the contact geometry. The equivalent plastic strain at integration points thus evolved with cycle number (Fig. 19). Elastic shakedown was reached when an asymptotic condition was reached.

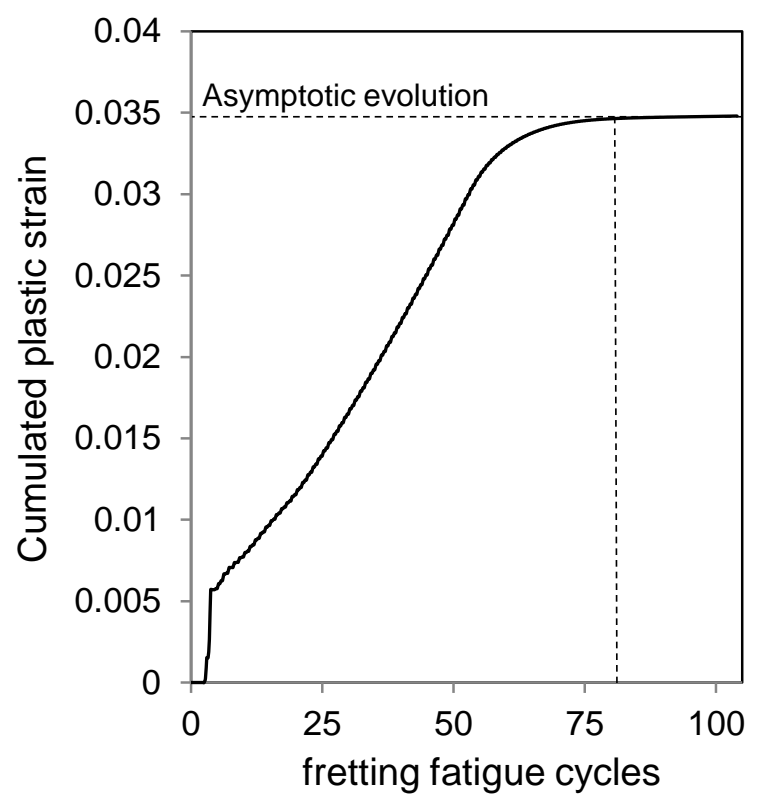

Fig. 19. Monitoring of elastic shakedown of crack arrest condition $\left(Q^{*} / \mu P=0.29\right.$, $\left.\sigma_{F} / \sigma_{y, 0.2 \%}=0.60\right)$ with monotonic elastic-plastic law

Numerical analysis showed that the elastic shakedown was achieved after around 20 loading cycles for plain fretting computation, which is 5 hours computation time. High loading conditions, like fretting fatigue, needed more than 80 loading cycle (that is around 1 day) to shake down as shown in Fig. 19. Usually, elastic shakedown is reached much more quickly [24], however really high level of plastic strain were investigated. Assuming an elastic Hertzian contact, the studied normal loading gives a maximum pressure $p_{0}=2.3 \sigma_{y, 0.2 \%}$. That is much more larger than the common Hertzian yield stress limit $p_{0, y i e l d}=1.6 \sigma_{y, 0.2 \%}$ [25]. Such difference allows understanding the very 
large time required to shake down and the very large plastic accommodation of the contact interface.

Considering the elastic shakedown state, an equivalent strategy to the one previously followed for elastic analysis was applied. Investigating experimental plain fretting crack nucleation and long crack arrest conditions we found $\ell_{E P}=28 \mu \mathrm{m}$ and $\Delta K_{0}$ $E P=5.5 \mathrm{MPa} \cdot \mathrm{m}^{1 / 2}$. Note that the obtained $\Delta \mathrm{K}_{0}$ is now much more realistic than the value extracted from the elastic investigation. Using these two variable and considering elastic-plastic hypothesis (EP), both fretting fatigue crack nucleation $\left(Q^{*}{ }_{C N-F F(E P)}\left(\ell_{E P}\right)\right)$ and crack arrest $\left(Q^{*}{ }_{C A-F F(E P)}\left(\ell_{E P}\right)\right)$ boundaries were computed. Fig. 21 plots the obtained map. Dotted lines are extrapolations until the plain fatigue limit $\sigma_{U T S}$.

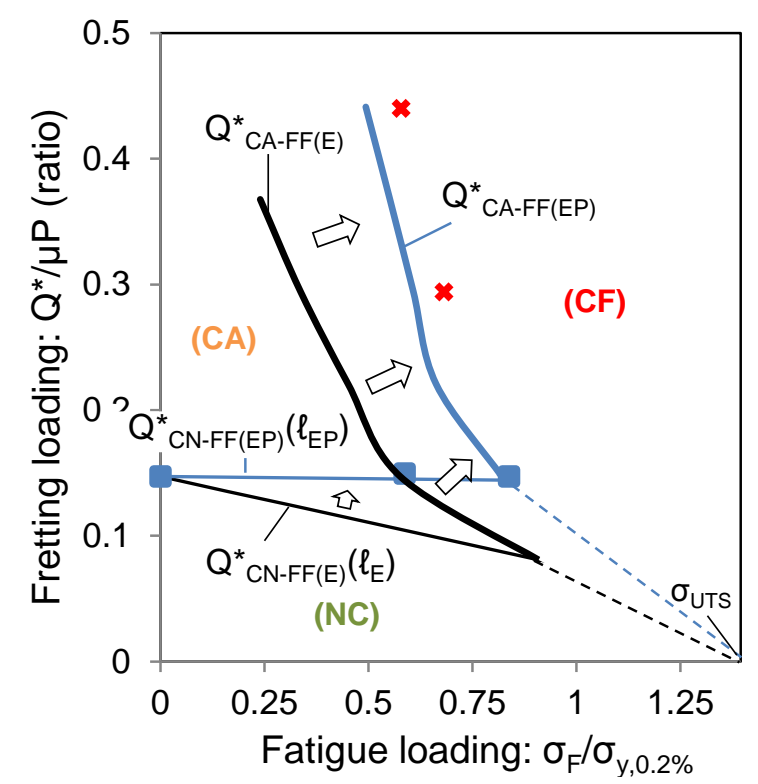

Fig. 20. Computed elastic crack nucleation $\left(-, Q^{*}{ }_{C N-F F(E)}\left(l_{E}\right)\right)$ and crack arrest $\left(-, Q^{*} C A-\right.$

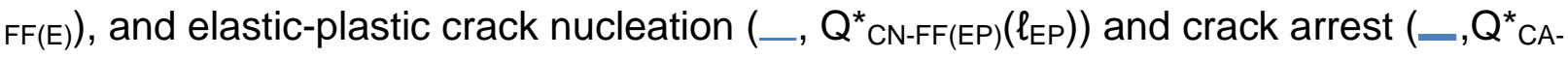
$F F(E P))$, boundaries in the fretting fatigue map. $X$ : Experimental crack arrest conditions. $\square$ : Experimental crack nucleation conditions. $\left(R=19 \mathrm{~mm}, 12 \mathrm{~Hz}, \mathrm{P}, \mathrm{R}_{\mathrm{F}}=0.94, \mathrm{R}_{\mathrm{Q}^{*}=-1}\right.$, $\left.\ell_{E P}=28 \mu m\right)$

Unlike elastic boundary, EP crack nucleation boundary displayed very good correlation

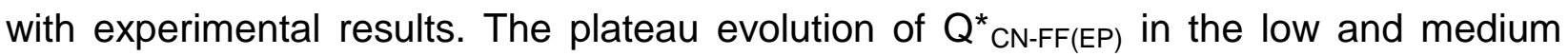
fatigue stress range $\sigma_{F} / \sigma_{y, 0.2 \%} \leq 0.84$ was well predicted. A similar conclusion was 
reached observing crack arrest response. The $Q^{*}{ }^{*} A-F F(E P)$ crack arrest boundary was still conservative compared to experimental results but the scattering was significantly reduced compared to the former elastic simulation.

To quantify the prediction the following error parameters were considered and plotted in Fig. 21:

$$
\begin{array}{ll}
\mathrm{E}_{\mathrm{CN}} \%=\frac{\mathrm{Q}_{C N(\exp }^{*}-Q_{C N(t h)}^{*} * 100}{\mathrm{Q}_{C N(\exp )}^{*}} & \left(0 \leq \sigma_{\mathrm{F}} / \sigma_{\mathrm{y}, 0.2 \%} \leq 0.84\right) \\
\mathrm{E}_{\mathrm{CA} \%}=\frac{\sigma_{\mathrm{CA}-\mathrm{FF}(\exp )}-\sigma_{\mathrm{CA}-\mathrm{FF}(\mathrm{th})}}{\sigma_{\mathrm{CA}-\mathrm{FF}(\exp )}} * 100 & \left(0.15 \leq \mathrm{Q}^{*} / \mu \mathrm{P} \leq 0.35\right)
\end{array}
$$

Using the $E_{C N} \%$ and $E_{C A} \%$ error indices we can easily quantify elastic and elastic-plastic predictions according that a similar reverse strategy was adopted for modeling the plain fretting experiments. The comparisons of Fig. 21 confirm that EP simulations drastically reduce the prediction error. The maximum errors regarding crack nucleation and crack arrest predictions are respectively reduced by 30 and 5 if EP simulations are considered. We conclude that although the monotonic plastic law assumption is far to be representative of the cyclic fretting fatigue stress condition, it appears sufficient to achieve good estimation of both crack nucleation and crack arrest fretting fatigue boundaries. 


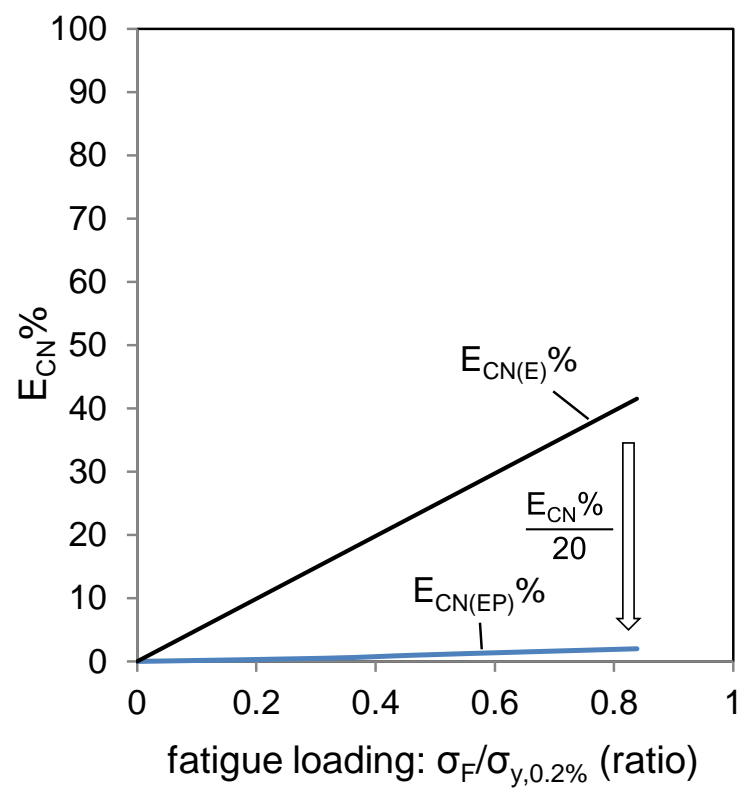

a-

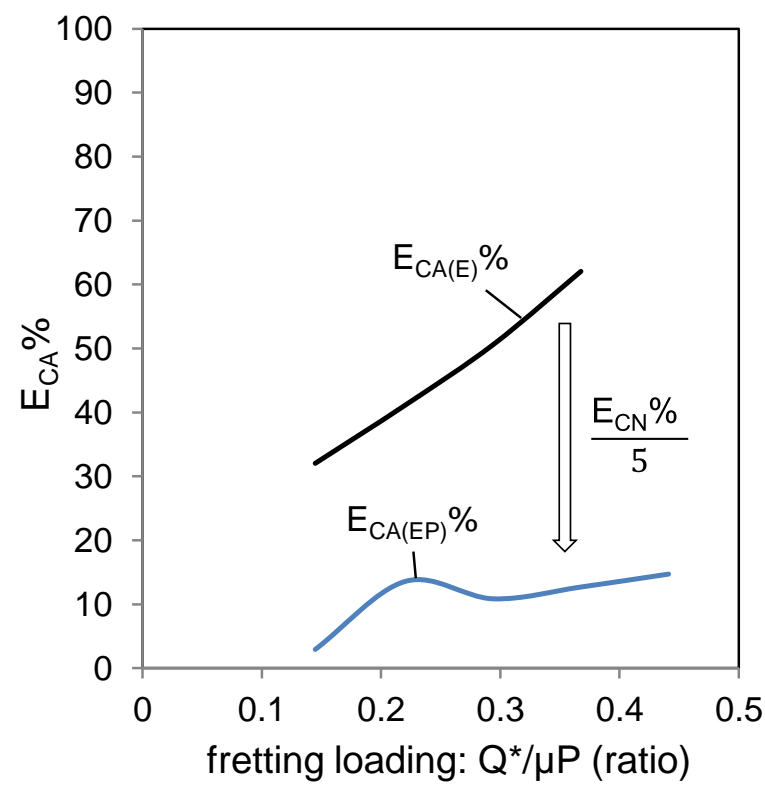

b-

Fig. 21. Crack nucleation (a) and crack arrest (b) prediction errors.

\section{Discussion}

To interpret the better correlation using EP simulations it must be underlined that combined fretting and fatigue stressing induce a significant plastic strain deformations in the contact region. This plastic deformation can affect the fretting fatigue interface in two aspects 
- First it generates a significant contact area extension which tends to flatten and reduce the contact pressure profile and consequently the maximum shear stressing $q_{\max }$ which was shown to be a controlling factor of the crack nucleation condition (Fig. 22) [20]. Hence assuming a constant $Q^{*}$ tangential force, an increase of the fatigue stress increase the contact plastic deformation promoting a flattening of surface pressure and shear profiles. The $\mathrm{q}_{\max }$ value is reduced as well as the cracking risk. This effect tends to compensate for the increase of stress induced by the increase of the fatigue load and finally can explain the plateau evolution of the $Q^{*}{ }_{C N-F F}$ crack nucleation boundary in the low and medium fatigue stress range $\sigma_{F} / \sigma_{y, 0.2 \%} \leq 0.84$. This aspect is taken into account by the EP simulations but cannot be addressed using a simple elastic analysis. Therefore it can be understood why EP simulations provide more representative predictions of the fretting fatigue crack nucleation boundary.

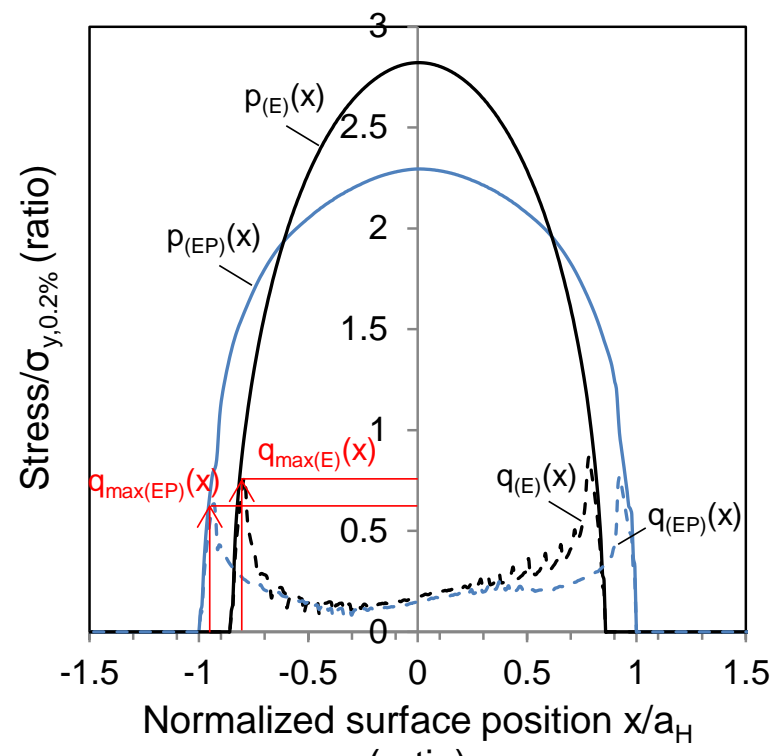

(ratio)

Fig. 22. Contact elastic and elastic-plastic pressure and shear profiles of plain fretting crack nucleation condition $Q^{*}{ }_{C N}\left(P, Q^{*} / \mu P=0.15\right), a_{H}$ : Hertzian elastic contact radius

- A second aspect induced by plastic deformations is the introduction of compressive residual stresses below the contact interface (Fig. 23). This aspect was shown to be not so critical regarding crack nucleation, as residual stresses converge to zero on the top surface where the crack nucleation is operating. But further below the 
surface, where the contact stresses are less significant such compressive residual stress can limit the crack propagation rate and extension. Hence the better prediction of the crack arrest boundary using EP FEM simulation can either be explained considering a better description of the surface stress fields but also stating that EP simulations simulate the pressure of compressive residual stresses in the SIF estimation.

Considering these two aspects (i.e. better description of the plastic contact accommodation and introduction of compressive residual stresses) it can be understood why EP simulation provides more realistic predictions of both crack nucleation $Q^{*}{ }_{C N}$-FF and crack arrest $Q^{*}{ }^{*}$ A-FF fretting fatigue boundaries. Cyclic elastic-plastic computation would probably provide better results being able to model more perfectly the cyclic fretting fatigue loading. However cyclic laws are difficult and expensive to identify while a really good estimation is proposed in this study with a simple monotonic description.

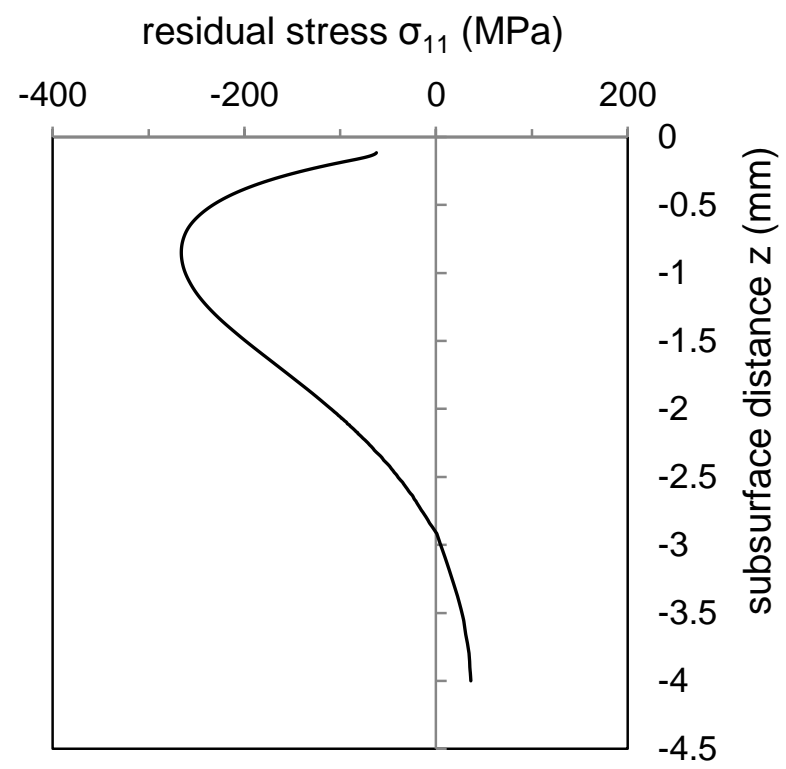

Fig. 23. Residual stress field computed at trailing contact border extracted after contact opening $\left(P, Q^{*} / \mu P=0.29, \sigma_{F} / \sigma_{y, 0.2 \%}=0.60\right)$ 


\section{Conclusion}

A fretting fatigue experimental analysis was done to identify the infinite endurance of a steel interface (crack nucleation and crack arrest boundaries). An experimental fretting fatigue map was achieved for severe plastic contact conditions representative of an industrial situation. A reverse identification strategy was applied on plain fretting cracking results. The non-local critical distance used to capture the stress gradient effect on crack nucleation, and the $\Delta \mathrm{K}_{0}$ threshold SIF range used to predict the crack arrest situation were extracted. This strategy was adapted considering elastic and elastic-plastic computation strategy. We showed that elastic simulation systematically leads to over conservative predictions. By contrast EP analysis involving a monotonic plastic law provided very good predictions of experiments (i.e. crack nucleation and crack arrest results), while still maintaining safe conservative predictions. Future development will be done to evaluate in how far a more representative cyclic plastic law can improve the prediction of the fretting fatigue map.

\section{References}

[1] R.B. Waterhouse, Fretting Fatigue, Waterhouse, 1981.

[2] D.A. Hills, Mechanics of fretting fatigue, Wear. 175 (1994) 107-113.

[3] C. Petiot, Développement d'une méthodologie prévisionnelle du comportement en frettingfatigue couplant les approches expérimentales et théoriques, Thèse de l'école centrale de Lyon, 1994.

[4] M.P. Szolwinski, T.N. Farris, Mechanics of fretting fatigue crack formation, Wear. 98 (1996) 93107.

[5] S. Fouvry, P. Kapsa, L. Vincent, A multiaxial fatigue analysis of fretting contact taking into account the size effect, ASTM STP. 1367 (2000) 167-182.

[6] J. Araújo, D. Nowell, The effect of rapidly varying contact stress fields on fretting fatigue, 24 (2002) 763-775.

[7] J.A. Araujo, D. Nowell, Analysis of pad size effects in fretting fatigue using short crack arrest methodologies, Int. J. Fatigue. 21 (1999) 947-956. 
[8] S. Munoz, C. Navarro, J. Dominguez, Application of fracture mechanics to estimate fretting fatigue endurance curves, Eng. Fract. Mech. 74 (2007) 2168-2186.

[9] R. Hojjati-Talemi, M.A. Wahab, Fretting fatigue crack initiation lifetime predictor tool: Using damage mechanics approach, Tribol. Int. 60 (2013) 176-186.

[10] R. Ferre, S. Fouvry, B. Berthel, R. Amargier, J.A. Ruiz-Sabariego, Prediction of the fretting fatigue crack nucleation endurance of a Ti-6V-4Al/Ti-6V-4Al interface: Influence of plasticity and tensile/shear fatigue properties, Proceedia Eng. 66 (2013) 803-812.

[11] S. Fouvry, K. Kubiak, Introduction of a fretting-fatigue mapping concept: Development of a dual crack nucleation - crack propagation approach to formalize fretting-fatigue damage, Int. J. Fatigue. 31 (2009) 250-262.

[12] C. Bosch, D. Delafosse, X. Longaygue, Effects of strain and trapping on hydrogen- induced cracking in high strength low alloy steels, Eur. Corros. Congr. 2010 (Eurocorr 2010). 2 (n.d.) 1158-1570.

[13] J. Meriaux, S. Fouvry, K. Kubiak, S. Deyber, Characterization of crack nucleation in TA6V under fretting-fatigue loading using the potential drop technique, Int. J. Fatigue. 32 (2010) 1658-1668.

[14] C.D. Lykins, S. Mall, V.K. Jain, Combined experimental - numerical investigation of fretting fatigue crack initiation, Int. J. Fatigue. 23 (2001) 703-711.

[15] H. Proudhon, S. Fouvry, G.R. Yantio, Determination and prediction of the fretting crack initiation: introduction of the $(P, Q, N)$ representation and definition of a variable process volume, Int. J. Fatigue. 28 (2006) 707-713.

[16] Y. Kondo, C. Sakae, M. Kubota, K. Yanagihara, Non-propagating crack behaviour at giga-cycle fretting fatigue limit, Fatigue Fract. Eng. Mater. Struct. 28 (2005) 501-506.

[17] H. Proudhon, S. Fouvry, J. Buffiere, A fretting crack initiation prediction taking into account the surface roughness and the crack nucleation process volume, Int. J. Fatigue. 27 (2005) 569-579.

[18] G.B. Voisin J.M., Vannes A.B, Vincent L., Daviot J., Analysis of a tube-grid oscillatory contact: methodology selection of superficial treatments, 183 (1995) 826-832.

[19] B. Crossland, Effect of large hydrostatic pressures on the torsional fatigue strength of an alloy steel, Proc. Int. Conf. Fatigue Met. (1956) 138-149.

[20] S. Fouvry, H. Gallien, B. Berthel, From uni- to multi-axial fretting-fatigue crack nucleation: Development of a stress-gradient-dependent critical distance approach, Int. J. Fatigue. (2013).

[21] H.F. Bueckner, Weight functions and fundamental fields for the penny shaped and the half plane crack in three spaces, Int. J. Solids Struct. 1987 (23AD) 57-93.

[22] D. Taylor, Geometrical effects in fatigue: a unifying theoretical model, Int. J. Fatigue. 21 (1999) 413-420. 
[23] A. de Pannemaecker, S. Fouvry, J.-Y. Buffiere, Introduction of a reverse simulation approach to identify the fatigue stress intensity factor crack arrest threshold from fretting cracking experiments, Tribol. Int. (2013).

[24] J.M. Ambrico, M.R. Begley, Plasticity in fretting contact, J. Mech. Phys. Solids. 48 (2000) 23912417.

[25] K. Johnson, Contact Mechanics, Cambridge University press, 1985. 